\title{
Editorial
}

\section{Nanotechnology for Electrooptical and Photovoltaic Devices}

\author{
Teen-Hang Meen, ${ }^{1}$ Stephen D. Prior, ${ }^{2}$ Liang-Wen Ji, ${ }^{3}$ and Yu-Jen Hsiao ${ }^{4}$ \\ ${ }^{1}$ Department of Electronic Engineering, National Formosa University, Yunlin 632, Taiwan \\ ${ }^{2}$ Aeronautics, Astronautics and Computational Engineering, The University of Southampton, Southampton SO17 1BJ, UK \\ ${ }^{3}$ Institute of Electro-Optical and Materials Science, National Formosa University, Yunlin 632, Taiwan \\ ${ }^{4}$ National Nano Device Laboratories, Tainan 741, Taiwan
}

Correspondence should be addressed to Teen-Hang Meen; thmeen@nfu.edu.tw

Received 1 December 2013; Accepted 1 December 2013

Copyright (C) 2013 Teen-Hang Meen et al. This is an open access article distributed under the Creative Commons Attribution License, which permits unrestricted use, distribution, and reproduction in any medium, provided the original work is properly cited.

Nanomaterials which provide one of the greatest potentials for improving performance and extended capabilities of products in a number of industrial sectors are a new class of materials, having dimensions in the $1 \sim 100 \mathrm{~nm}$ range. Nanostructures can be divided into zero-dimensional, onedimensional, and two-dimensional based on their shapes. The recent emphasis in the nanomaterials research is put on $1 \mathrm{D}$ nanostructures at the expense of $0 \mathrm{D}$ and $2 \mathrm{D}$ ones, perhaps due to the intriguing possibility of using them in a majority of short-term future applications. The most successful examples are seen in the microelectronics, where "smaller" has always meant a greater performance ever since the invention of transistors, for example, higher density of integration, faster response, lower cost, and less power consumption.

In recent years, optoelectronic and solar cells devices have been a highly developing field, due to the flexibility and light weight for energy conversion, which has the potential to be deployable. Therefore, the field of electrooptical and photovoltaic devices has been the subject of reviews. Electrooptical and photovoltaic devices are environmentally sustainable, in particular considering the availability of the nanostructured raw materials. Science and technology developments in electrooptical and photovoltaic devices over the next several years and their influence on the economics of electrooptical and PV installations are likely to establish which energy technologies become dominant for decades to come. The chance to share and discuss these crucial electrooptical and PV developments in a timely and influential forum is important.
This special issue selects 19 papers about dye-sensitized solar cells, small molecule organic solar cells, ZnS/ $\mathrm{CuIn}_{1-x} \mathrm{Ga}_{x} \mathrm{Se}_{2}$ solar cell, thin-film solar cells, photovoltaic devices, and other related fields. This special issue enables interdisciplinary collaboration between science and engineering technologists in the academic and industrial fields.

Teen-Hang Meen Stephen D. Prior Liang-Wen Ji Yu-Jen Hsiao 

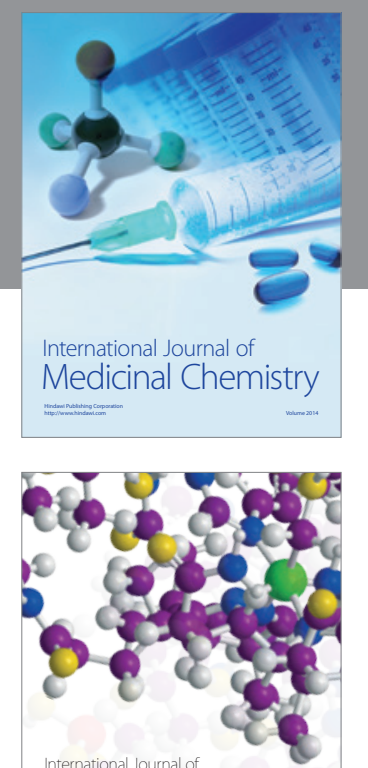

\section{Carbohydrate} Chemistry

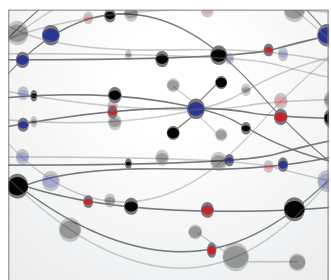

The Scientific World Journal
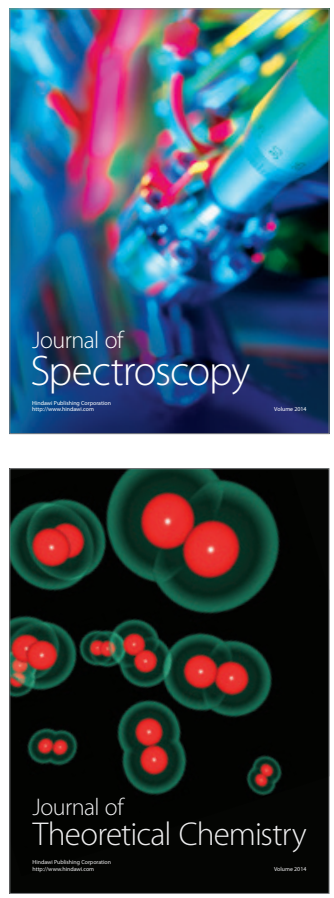
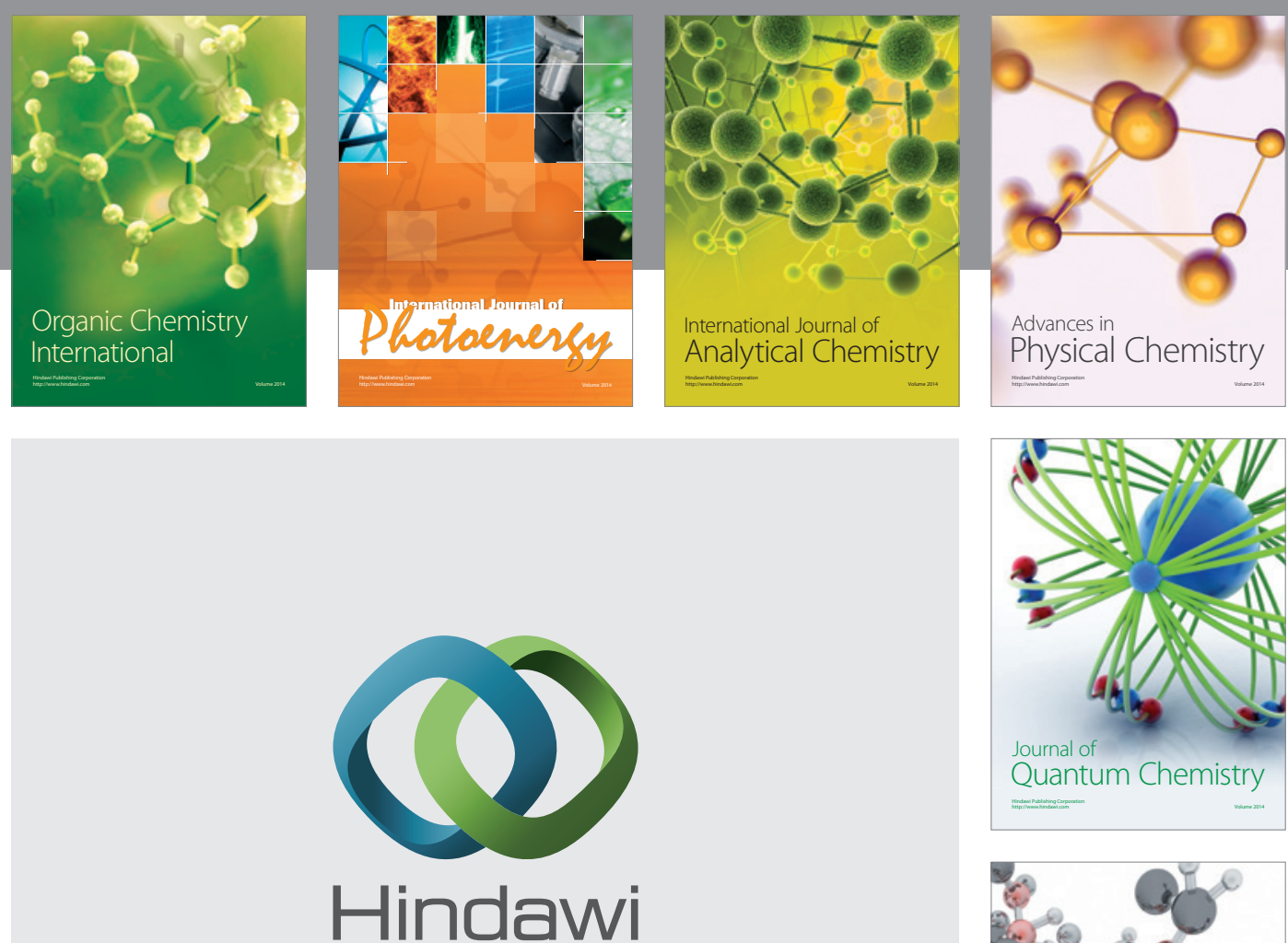

Submit your manuscripts at

http://www.hindawi.com

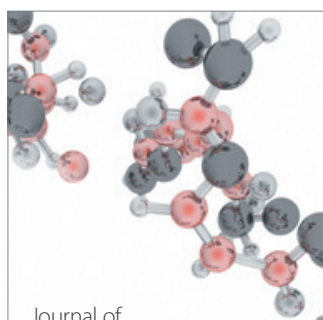

Analytical Methods

in Chemistry

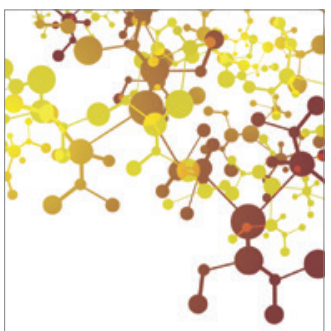

Journal of

Applied Chemistry

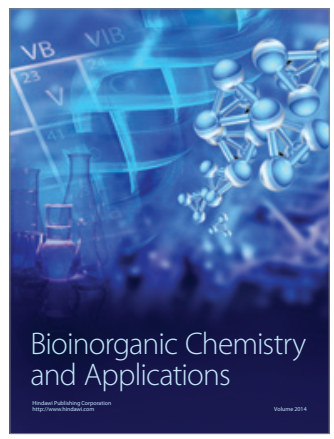

Inorganic Chemistry
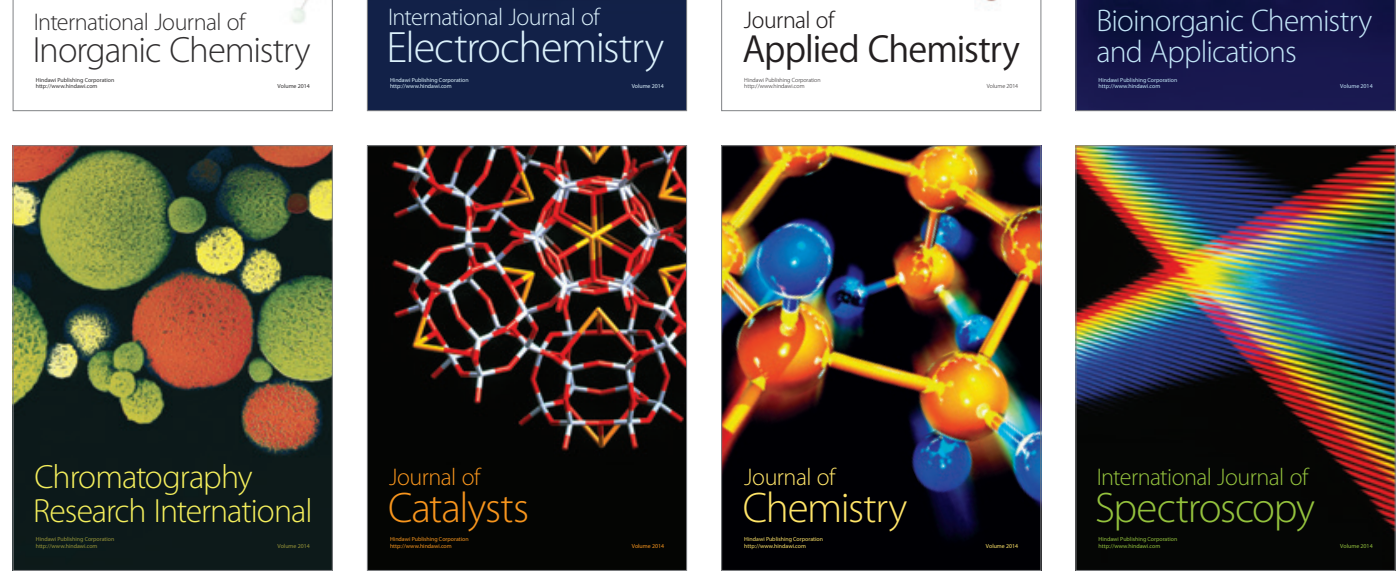